ISSN 1817-3721, E-ISSN 1818-8745

Plant Tissue Cult. \& Biotech. 29(1): 33-47, 2019 (June)

CBangladesh Assoc. for Plant Tissue Culture \& Biotechnology

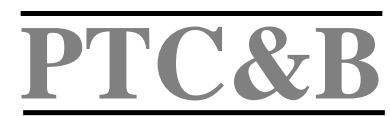

\title{
Plant Regeneration in Buckwheat (Fagopyrum esculentum Moench.) via Somatic Embryogenesis and Induction of Meristemoids in Abnormal Embryos
}

\author{
Ribha Saraswat and Mithilesh Kumar* \\ School of Life Sciences, Jaipur National University, Jagatpura, Jaipur-302017 (Rajasthan), India \\ Key words: Buckwheat, Fagopyrum esculentum, Somatic embryogenesis, Abnormal somatic \\ embryos, Shoot organogenesis
}

\begin{abstract}
An efficient in vitro regeneration protocol is reported for common buckwheat. A combination of $0.5 \mathrm{mg} / 2,4-\mathrm{D}$ and $0.2 \mathrm{mg} / \mathrm{BAP}$ with sucrose showed highest induction of somatic embryogenesis from cotyledon and hypocotyl explants. More than $35 \%$ of normal somatic embryos matured on MS. MS with $2 \%$ sucrose were found best for germination and conversion of somatic embryos to plantlets. In tissue culture, abnormal somatic embryos usually occur. In this report, abnormal embryos are also used to induce shoot organogenesis, adding to the number of final regenerants and ensuring full utilization of regenerative propagules. A treatment of $0.2 \mathrm{mg} \Lambda$ BAP induced meristemoids in $60 \%$ of underdeveloped embryos and a combination of $0.5 \mathrm{mg} / \mathrm{BAP}$ and $0.5 \mathrm{mg} / \mathrm{AgNO}_{3}$ led browning and senescence-free progression of shoot buds to well developed shoots, which were subsequently rooted in half strength MS containing $2 \%$ sucrose and $0.25 \mathrm{mg} / \mathrm{IBA}$. The regenerated plants survived acclimatization, flowered and set seeds.
\end{abstract}

\section{Introduction}

Common buckwheat, Fagopyrum esculentum Moench. is an annual and has been popular as a food crop of Eurasia receiving worldwide attention for its enhanced taste (Woo et al. 2016). The demand for buckwheat is due to its excellent nutritional value based on the favorable composition of gluten-free protein complex with high content of lysine (5\%), well balanced quantity of essential amino acids, fibrous material, minerals, vitamins and also because of its very low content of prolamine (Michalova et al. 1998). The higher content of digestion-tolerant albumin protein and starches in buckwheat seeds makes it quite complementary to cereal flours (Kawa et al. 2003). The medicinal value of buck-

*Author for correspondence: <mithileshkumarbio@gmail.com>.

DOI: https://doi.org/10.3329/ptcb.v29i1.41977 
wheat is due to presence of flavones, flavonoids, sterols, fagopyrin, and thiamin-binding proteins (Li et al. 2001). Out of all the bioflavonoids that buckwheat contains, the chief component is rutin (Jiang 2007), which in moderate amounts can act as potent antiinflammatory, anti-thrombotic, anti-mutagenic, anti-oxidant, cytoprotective; and has the ability to protect against cardiovascular diseases and cancer (Ganeshpurkar and Saluja 2017).

Buckwheat grows well in moist and cool climate. As it can grow in rather poor soils, its products are deemed to be a low-cost supplement to cereal grains. Buckwheat never accomplished the status of vital crop for cultivation and was never widely adopted, in spite of all its interesting potentials. Obstacles behind the limited conventional breeding are its strong self/cross incompatibility (Neskovic et al. 1995), flower abortion (Morris 1951), low seed set, seed shattering (Oba 1998), uncertain sort of growth and blooming, lodging and its susceptibility to spring and fall frost. Vegetative propagation through cuttings or other conventional methods has not been successful in buckwheat. With the advent of plant biotechnological techniques, it has become possible to incorporate those traits in the plant germplasms, which are not found in them or in any of their wild relatives. However, to accomplish genetic transformation of a plant species and to generate stable transgenic lines, reproducible in vitro regeneration systems are often required.

Several efforts have been made to study in vitro regeneration in Fagopyrum esculentum Moench. The in vitro plant regeneration and genetic transformation reports in Fagopyrum spp. and the related gap areas have extensively been reviewed in Kumar and Saraswat (2018). Yamane (1974) induced differentiation of buckwheat shoots from seed derived callus. Serjovic and Neskovic 1981 described stages of buckwheat explants growth via organogenic mode. Later, shoot organogenesis was established and reported with different explants such as cotyledon (Luthar and Marchetti 1994, Berbec and Doroszewska 1999, Klcova and Gubisova 2008, Lee et al. 2009), hypocotyl (Berbec and Doroszewska 1999, Jin et al. 2002, Klcova and Gubisova 2008, Hou et al. 2014, Adachi et al. 1989, Lachman and Adachi 1990), leaf (Woo et al. 2004), leaf petiole (Slawinska et al. 2009) and nodal segment (Kachonpadungkitti et al. 2001, Klcova and Gubisova 2008, Chen et al. 2012, Majid et al. 2015), utilizing various media regimens and obtaining varying frequencies. Regeneration ability via somatic embryogenesis has been published in a few reports using immature zygotic embryo (Neskovic et al. 1987), leaf and stem (Park et al. 1999), cotyledon (Woo et al. 2000, Wang et al. 2016), hypocotyl (Gumerova et al. 2003, Han et al. 2011, Wang et al. 2016, Kwon et al. 2013). However, no reports are available on the investigation of the best carbon source and explant type for somatic embryogenesis based in vitro regeneration in common buckwheat.

The paper reports an efficient method of in vitro plant regeneration in F. esculentum Moench. This study compares various parameters, to determine the relative efficacy of 
carbon sources, the plant growth regulators combinations and the most efficient explant type for not only induction of somatic embryogenesis in buckwheat but also on the proliferation, maturation and conversion of somatic embryos.

\section{Materials and Methods}

Mature seeds of Fagopyrum esculentum Moench. were obtained from Organic Seeds, Dehradun (India). Seeds were surface sterilized for $4 \mathrm{~min}$ using $0.1 \%$ (w/v) $\mathrm{HgCl}_{2}$ followed by four times washing with sterile distilled water to remove traces of $\mathrm{HgCl}_{2}$. Sterilized seeds were then immersed in sterile distilled water for $12 \mathrm{hrs}$. Imbibed seeds were placed in Petri dishes on moistened filter paper for germination. After germination, 7 day-old-seedlings were transferred on filter paper bridges in test tubes containing $20 \mathrm{ml}$ half strength MS liquid medium.

Two independent set of experiments were performed to evaluate the individual effect of two carbon sources, namely sucrose and glucose along with PGRs (2,4-D and BAP) on somatic embryogenesis in Fagopyrum esculentum. The cotyledon and hypocotyl explants from 12 day-old-seedlings were inoculated aseptically and cultured on callus induction and proliferation medium (CIPM) having various PGRs regimen and different carbon sources. The basal medium of CIPM used composed of MS salts, Gamborg (1968) vitamins, $30 \mathrm{~g} /$ sucrose or glucose, $100 \mathrm{mg} / \mathrm{myo}$-inositol and $0.8 \%(\mathrm{w} / \mathrm{N})$ agar. A total of eight different PGR combinations of 2,4-D (0.5 - $2.0 \mathrm{mg} /)$ and BAP $(0.2-1.0 \mathrm{mg} /)$ with both sucrose and glucose separately were tested. After two subculturing cycles in CIPMsucrose (CIPM-S-1 to CIPM-S-8) and CIPM-glucose (CIPM-G-1 to CIPM-G-8), the proliferating calli were transferred to respective somatic embryogenesis induction media (SEIM-sucrose or SEIM-glucose medium). The SEIM was identical to CIPM except that no PGR was added and Gamborg (1968) vitamins were replaced with MS vitamins. Cultures were subcultured to fresh medium with their respective carbon source, every 25 - 28 days. The somatic embryogenesis induction frequency (SEIF) in cultures derived from any treatment was scored. Cultures in any treatment were simultaneously scored for proliferation of embryogenic calli. For maturation, globular stage somatic embryos with associated embryogenic callus were transferred to fresh MS with and without additional $1.9 \mathrm{~g} /$ of $\mathrm{KNO}_{3}$ to observe the effect of additional potassium and nitrate ions on maturity of somatic embryos. These treatments were designated as SEMM1, SEMM2 (with sucrose), and SEMM3 and SEMM4 (with glucose). Normal, bipolar torpedo stage mature somatic embryos (SEs) derived from the SEMM1 to SEMM4 treatments were transferred individually to MS based medium (SEGM1 to SEGM4). In these germination medium treatments, MS of half or full strength were used along with either $0.2 \mathrm{mg} / \mathrm{GA}_{3}$ or additional $950 \mathrm{mg} /$ of $\mathrm{KNO}_{3}$. All media contained $2 \%(\mathrm{w} / \mathrm{N})$ sucrose as carbon source and solidified with $0.8 \%(\mathrm{w} /)$ ) agar. Cultures were passaged to fresh medium with same concentrations of additives after every 3-weeks incubation. 
Underdeveloped, abnormal and/or fused somatic embryos (AEs) obtained during embryogenic proliferation or maturation stage were selected and vertically placed on meristemoid and shoot induction medium (MSIM). MSIM consisted of MS salts and vitamins, $3 \%(\mathrm{w} / \mathrm{N})$ sucrose, $0.8 \%(\mathrm{w} / \mathrm{N})$ agar supplemented with various concentrations of BAP $(0.1-0.5 \mathrm{mg} /)$. The MS basal medium with $3 \%(\mathrm{w} / \mathrm{N})$ sucrose was used as negative control. Induced meristemoids were separated and subcultured at every two weeks on fresh MSIM for multiplication and further growth of shoots. In order to overcome browning of newly developed shoots/leaves and for improving shoot growth, the in vitro culture derived shoots via meristemoid induction were excised and cultured on MS having various doses of $\mathrm{AgNO}_{3}(0.1-0.5 \mathrm{mg} \Lambda$ ) with and without BAP (0.1 - 0.5 $\mathrm{mg} /$ ) in $150 \mathrm{ml}$ conical flasks shoot clumps as well as individual shoots were frequently subcultured onto fresh medium containing the same, respective $\mathrm{AgNO}_{3}$-BAP media combinations at two weeks intervals. $3-10 \mathrm{~cm}$ long shoots with at least two pairs of true leaves were excised and transferred to four different media (RIM1 - RIM4) in $250 \mathrm{ml}$ conical flasks for root induction. The RIMs contained MS of full or half strengths either alone or supplemented with $0.25 \mathrm{mg} / \mathrm{IBA}$. The root induction per shoot was recorded 15 days post culturing onto these media.

SEs- and AEs- derived well-developed plantlets with more than two completely prolonged true leaves and root system were taken out from semi-solid medium and transferred to Jam bottles having $50 \mathrm{ml}$ of sterile Hoagland solution. After 3 - 4 days, plantlets were taken out and gently washed under running tap water to remove the traces of agar. The plantlets were subsequently transplanted into plastic cups containing potting mix (having garden soil, coarse sand and vermiculite in $1: 1: 1$ ratio) and irrigated with half strength Hoagland salt solution. The plastic cups were covered with polythene bags and kept in the culture room. After a week, pores were created in bags, before removing them fully.

During the entire study, all the culture media were set at $\mathrm{pH}$ of 5.8 and were sterilized at $15 \mathrm{psi}$ for $15 \mathrm{~min}$. All cultures were maintained under $16 \mathrm{hrs}$ photoperiod and at a temperature of $25 \pm 2^{\circ} \mathrm{C}$ except during seeds germination where it was incubated at $18 \mathrm{hrs}$ photoperiod. The light was provided by fluorescent tubes having intensity of 60 $\mathrm{uEm}^{-2} \mathrm{~s}^{-1}$ at culture level. Unless stated specifically, each experiment was having complete random design and was repeated twice. Initially for callus induction, 18 hypocotyl and 15 cotyledon explants were inoculated in each treatment. The effect of different treatments was analyzed using one-way ANOVA, and their means were compared using the Tukey - HSD test at the 0.01 and $0.05 \%$ level of significance.

\section{Results and Discussion}

A protocol with full utilization of regenerative propagules via somatic embryogenesis was developed for in vitro regeneration in an Indian cultivar of Fagopyrum esculentum. To 
obtain callus mediated indirect regeneration, embryonic parts like hypocotyls and cotyledons from aseptically grown 12-day-old seedlings were the explants. Calli started appearing over cut edges of the explants within a period of $7-10$ days of culturing the explants and by the 15th day, it was easily observable (Fig. 1). Callus induction was observed at all the tested media combinations containing PGRs (Table 1). Hypocotyl explants showed a better response for callus induction and proliferation (92-100\%) on medium with glucose, whereas cotyledon explants showed better results $(75-100 \%)$ with sucrose. Although inclusion of sucrose or glucose did not significantly affect callus induction and proliferation in any explants type, various PGR treatments significantly
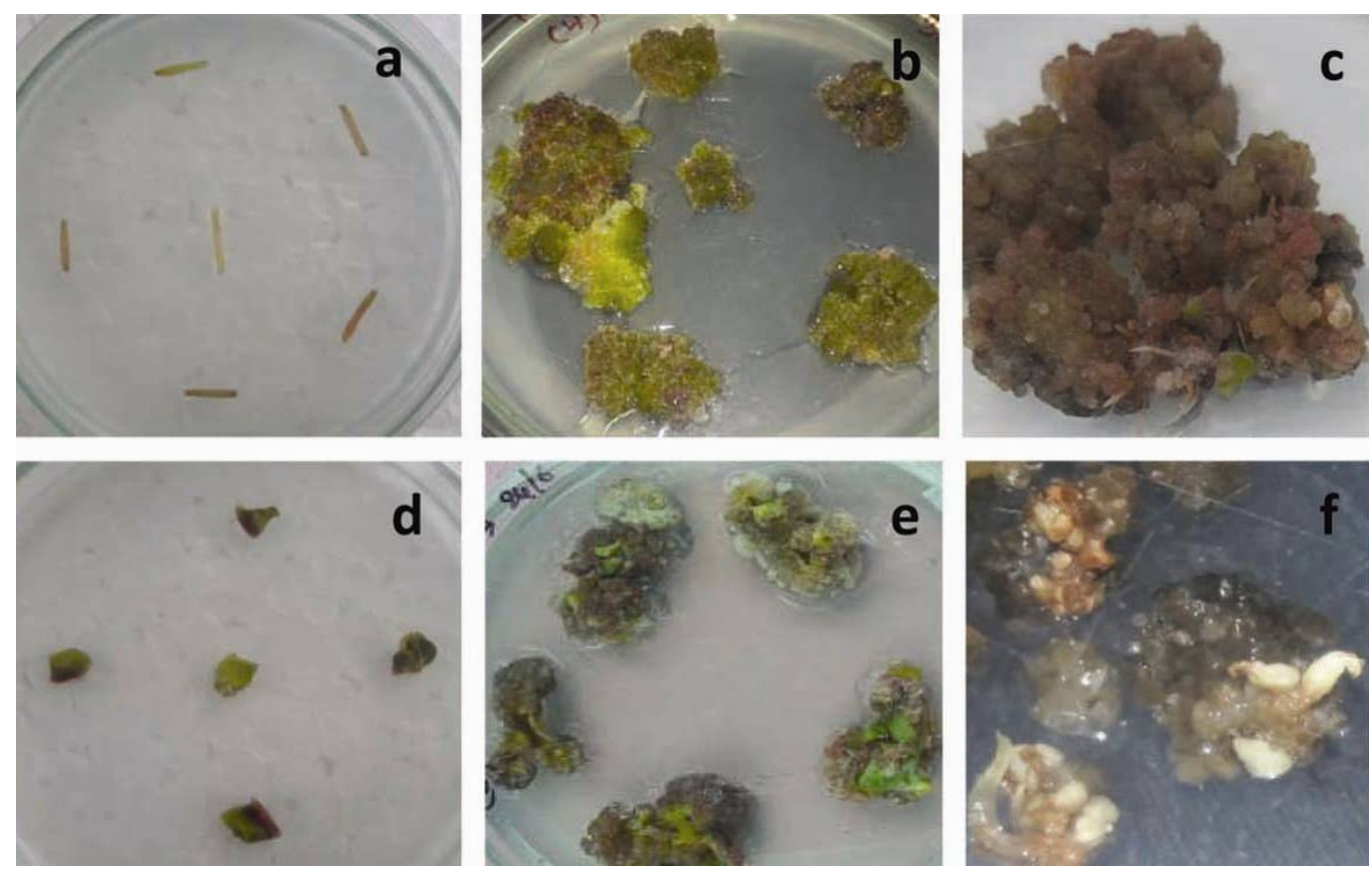

Fig. 1. Callus and embryogenesis induction in hypocotyl and cotyledon explants of F. esculentum. (a) Hypocotyl explants inoculated on CIPM plate, (b) callus proliferation in hypocotyl explants, (c) Appearance of embryogenic callus and somatic embryos in hyocotyl derived callus, (d) cotyledon explants inoculated on CIPM plate, (e) callus proliferation in cotyledon explants and (f) Appearance of embryogenic callus and somatic embryos in cotyledon derived callus.

differed in both cotyledon and hypocotyl over sucrose or glucose. Sucrose media combinations CIPM-S-1, CIPM-S-3 and CIPM-S-7 induced calli in almost all the explants resulting 100\% callus induction. CIPM-S-8 induced calli in all hypocotyl explants, but in cotyledons, it induced calli in only $75 \%$ of explants. Other sucrose media combinations also produced calli but their response differed. In glucose media combinations, CIPMG-3 and CIPM-G-4 induced callus in nearly all explants. However, CIPM-G-1, CIPM-G-2, 
CIPM-G-5 and CIPM-G-8 efficiently induced calli in all hypocotyl explants cultured over them, but response of cotyledon in these combinations differed (Table 1). The calli initially produced on these CIPMs were compact to loose, grew slowly and were nonmorphogenic. Calli growth was observed when the initial calli were passaged to fresh medium of same composition in subsequent subculturing cycles. The compact calli were white to greenish whereas loose calli ranged from yellowish to greenish, soft and watery. It was these loose calli which subsequently gave rise to highly proliferative calli, which in turn, eventually developed friable nature after transfer to PGR-free somatic embryogenesis induction media (SEIMs).

Table 1. Effect of different concentrations of 2,4-D and BAP on callus induction and somatic embryogenesis from hypocotyl and cotyledon explants of $F$. esculentum in medium containing different types of carbon sources.

\begin{tabular}{|c|c|c|c|c|c|c|}
\hline \multirow[b]{2}{*}{$\begin{array}{l}\text { Media } \\
\text { treatment(s) }\end{array}$} & \multicolumn{2}{|c|}{$\begin{array}{l}\text { PGR } \\
\text { composition }\end{array}$} & \multicolumn{2}{|c|}{$\begin{array}{c}\begin{array}{c}\text { Hypocotyl } \\
\text { explants }\end{array} \\
\end{array}$} & \multicolumn{2}{|c|}{$\begin{array}{c}\text { Cotyledon } \\
\text { explants }\end{array}$} \\
\hline & $\begin{array}{l}2,4-\mathrm{D} \\
(\mathrm{mg} \Lambda)\end{array}$ & $\begin{array}{l}\text { BAP } \\
(\mathrm{mg} /)\end{array}$ & $\begin{array}{l}\text { Callus } \\
\text { induction } \\
\text { frequency } \\
(\mathrm{CIF}) \% \pm \mathrm{SE}\end{array}$ & $\begin{array}{l}\text { Somatic embryo- } \\
\text { genesis } \\
\text { induction } \\
\text { frequency (SEIF) } \\
\% \pm \text { SE }\end{array}$ & $\begin{array}{l}\text { Callus } \\
\text { induction } \\
\text { frequency } \\
\text { (CIF) } \% \pm \mathrm{SE}\end{array}$ & $\begin{array}{l}\text { Somatic embryo- } \\
\text { genesis } \\
\text { induction frequency } \\
\text { (SEIF) } \% \pm \text { SE }\end{array}$ \\
\hline \multicolumn{7}{|c|}{ Sucrose as carbon source } \\
\hline CIPM-S-1 & 0.5 & 0.2 & $100 \pm 0$ & $83.33 \pm 3.21^{\mathrm{a}}$ & $100 \pm 0$ & $48.88 \pm 2.22^{\mathrm{a}}$ \\
\hline CIPM-S-2 & 1 & 0.2 & $79.62 \pm 1.85$ & $72.22 \pm 6.41^{\mathrm{ab}}$ & $95.55 \pm 2.22$ & $0^{\mathrm{d}}$ \\
\hline CIPM-S-3 & 2 & 0.2 & $100 \pm 0$ & $53.70 \pm 6.68^{\mathrm{bc}}$ & $100 \pm 0$ & $35.55 \pm 2.22^{\mathrm{b}}$ \\
\hline CIPM-S-4 & 0.5 & 0.5 & $74.07 \pm 4.90$ & $0 \mathrm{~g}$ & $88.89 \pm 4.44$ & $0^{\mathrm{d}}$ \\
\hline CIPM-S-5 & 1 & 0.5 & $77.77 \pm 3.21$ & $46.29 \pm 1.85^{\mathrm{cd}}$ & $86.66 \pm 3.85$ & $0^{\mathrm{d}}$ \\
\hline CIPM-S-6 & 2 & 0.5 & $83.33 \pm 3.21$ & $0 \mathrm{~g}$ & $80 \pm 0$ & $0^{\mathrm{d}}$ \\
\hline CIPM-S-7 & 0.5 & 1 & $100 \pm 0$ & $42.59 \pm 4.90^{\text {cde }}$ & $100 \pm 0$ & $22.22 \pm 2.22^{c}$ \\
\hline CIPM-S-8 & 1 & 1 & $100 \pm 0$ & $31.48 \pm 6.68^{\mathrm{def}}$ & $75.55 \pm 2.22$ & $0^{\mathrm{d}}$ \\
\hline \multicolumn{7}{|c|}{ Glucose as carbon source } \\
\hline CIPM-G-1 & 0.5 & 0.2 & $100 \pm 0$ & $51.85 \pm 1.85^{\mathrm{a}}$ & $93.30 \pm 0.01$ & $0^{c}$ \\
\hline CIPM-G-2 & 1 & 0.2 & $100 \pm 0$ & $46.29 \pm 1.85^{\mathrm{a}}$ & $84.43 \pm 4.43$ & $0^{c}$ \\
\hline CIPM-G-3 & 2 & 0.2 & $100 \pm 0$ & $0^{c}$ & $100 \pm 0$ & $20.11 \pm 2.02^{a}$ \\
\hline CIPM-G-4 & 0.5 & 0.5 & $98.15 \pm 1.85$ & $0^{c}$ & $100 \pm 0$ & $8.88 \pm 1.35^{\mathrm{b}}$ \\
\hline CIPM-G-5 & 1 & 0.5 & $100 \pm 0$ & $20.36 \pm 3.70^{b}$ & $82.20 \pm 5.88$ & $0^{c}$ \\
\hline CIPM-G-6 & 2 & 0.5 & $94.44 \pm 0$ & $14.81 \pm 1.85^{\mathrm{b}}$ & $75.53 \pm 2.23$ & $0^{c}$ \\
\hline CIPM-G-7 & 0.5 & 1 & $92.59 \pm 1.85$ & $0^{c}$ & $80 \pm 0$ & $0^{c}$ \\
\hline CIPM-G-8 & 1 & 1 & $100 \pm 0$ & $0^{c}$ & $75.53 \pm 2.23$ & $0^{c}$ \\
\hline
\end{tabular}

Data were pooled from three independent experiments. The effect of media treatments on SEIF were subjected to one way ANOVA and means were compared using Tukey-HSD test. Values that are significantly different at 0.01 and $0.05 \%$ probability levels are represented by different letters within column. Values that have same letters are non-significant. 
Highly proliferative calli developed over CIPMs were transferred to respective PGRfree SEIMs. Embryogenic callus emerged as dark brown to purplish brown, friable callus on the top or sides of parent callus as early as 2nd passage to this medium and showed at their surface conical creamish structures which eventually developed into somatic embryos. Figs 1 and 2 show callus proliferation and induction of somatic embryogenesis in hypocotyl and cotyledon explants. Globular stage somatic embryos continued to appear on the surface of embryogenic calli in subsequent subculturing cycles, whereas, embryogenic calli kept on proliferating. Somatic embryos were bigger in size than their zygotic counter parts and once induced, somatic embryogenesis in common buckwheat has been found to be self proliferating and embryogenic callus could
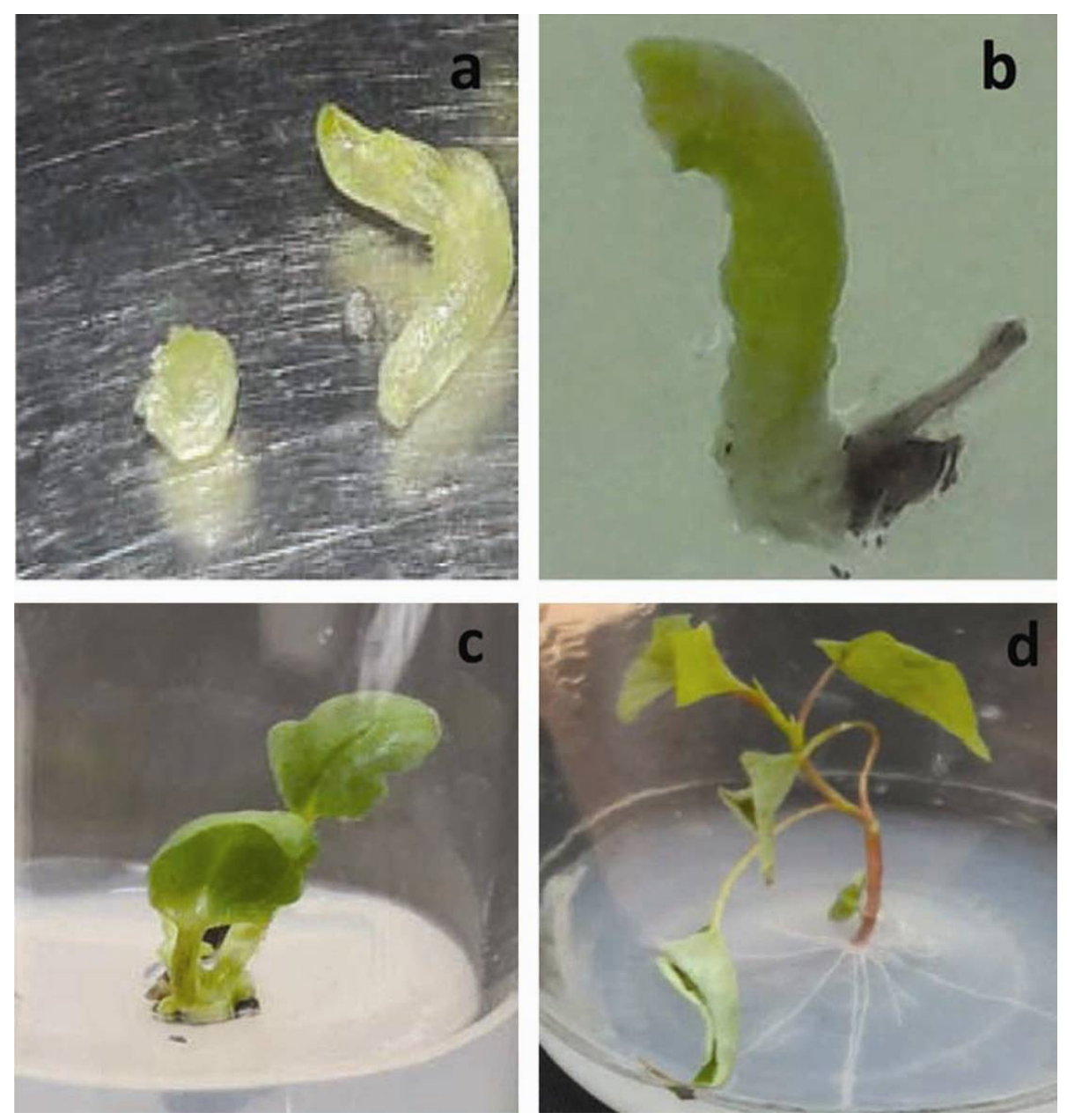

Fig. 2. Progression of F. esculentum somatic embryos to plantlets: (a) and (b) development and maturation of normal somatic embryos, (c) and (d) germination and conversion of somatic embryos to plantlets. 
be maintained in this state, unaided by any PGR, for at least 6 - 8 subulturing cycles. In subsequent subculturing cycles, however, it was noticed that number of abnormal embryos gets significantly higher in comparison to normal embryos. Out of all the PGR treatments tested in sucrose-based media, CIPM-S-1 (0.5 mg/2,4-D and $0.2 \mathrm{mg} / \mathrm{BAP}$ ) showed highest induction of embryogenesis in both hypocotyl $(83.33 \%)$ and cotyledon $(48.88 \%)$ explants derived calli (Table 1). No embryogenic induction was noticed in CIPM-S-4 and CIPM-S-6. Other sucrose media based PGR treatments (CIPM-S-2, -3, -5, -7 and -8 ) showed $32-72 \%$ somatic embryogenesis induction frequency (SEIF) in hypocotyl, whereas cotyledon derived calli showed induction only in CIPM-3 (35.5\% SEIF) and CIPM-7 (22.22\% SEIF). In glucose based media treatments, CIPM-G-3 and CIPM-G-4 induced embryogenesis in cotyledon calli (20 and $8.88 \%$, respectively). Interestingly, calli developed on hypocotyl in CIPM-G-1, CIPM-G-2, CIPM-G-5 and CIPM-G-6 showed $51.85,46.29,20.36$ and $14.81 \%$ SEIF, respectively (Table 1). Analysis of variance and a Tukey -HSD test with pair-wise comparison of the observations showed that (1) PGR treatments were significantly different in terms of their efficiency in inducing somatic embryogenesis in common buckwheat - CIPM-S-1 being the best, (2) hypocotyls are significantly better explants for in vitro regeneration and (3) sucrose is a significantly better carbon source for embryogenic induction.

Four different PGR-free MS (SEMM1 - SEMM4) were used for maturation of somatic embryos. Fig. 3 shows that SEMM2 and SEMM4 supported significantly high proportion of somatic embryos to achieve maturation, as compared to SEMM1 and SEMM3. The results thus show that in F. esculentum, additional $\mathrm{KNO}_{3}$ is not of much help for maturation of somatic embryos, as is reported in somatic embryogenesis in other species, for example, cotton (Trolinder and Goodin 1987). Around 35.55\% of hypocotyl explants derived somatic embryos and $22.22 \%$ of cotyledon explants derived somatic embryos attained maturity in sucrose based SEMM-2 and turned out in bipolar torpedo stage. Similarly, $24.44 \%$ of somatic embryos developed from hypocotyl explants and $15.5 \%$ of somatic embryos developed from cotyledon explants achieved maturity in glucose based SEMM-4. Additional $\mathrm{KNO}_{3}$ concentration in media resulted in change in embryo colour, and most of the embryos failed to mature even after a prolonged culture period. The reasons of getting low maturity of somatic embryos with additional $\mathrm{KNO}_{3}$ can be attributed to the fact that buckwheat is a salt stress sensitive crop.

Mature, bipolar somatic embryos with clear shoot and root ends from SEMMs were pooled and randomized over four germination media treatments (SEGMs). Fig. 2 shows the maturation and progression of buckwheat somatic embryos to plantlets. Within one month of transferring embryos to these media, germinating embryos (which earlier were creamish to yellowish brown) started turning green, a sign of entering to vegetative phase. Appearance of true leaves from shoot end, and roots along with branches from root end were scored as germination frequency in every treatment. Highest germination 
was recorded in SEGM1 (60\%). Again, here at this step, SEGM4 containing additional $0.95 \mathrm{~g} /$ of $\mathrm{KNO}_{3}$ did not result in any germination of embryos. SEGM2 having half strength MS led $28.9 \%$ of somatic embryos to germinate, whereas only $13.3 \%$ embryos germinated in $0.2 \mathrm{mg} / \mathrm{GA}_{3}$ supplemented SEGM3. The results presented in Table 2, therefore, indicated that lowering of sucrose concentration had far more marked influence on germination of somatic embryos in buckwheat than adding additional salts, or gibberellins.

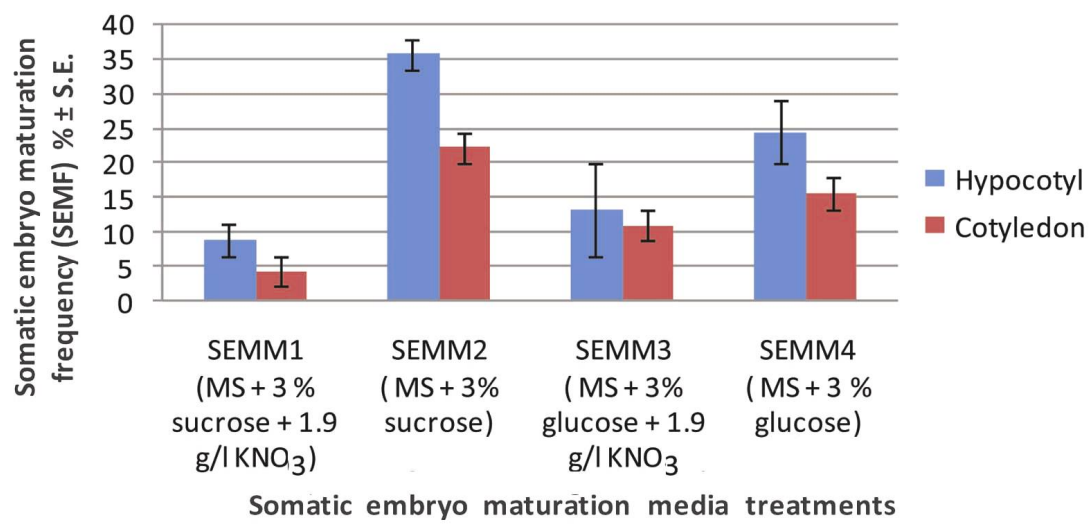

Fig. 3. F. esculentum somatic embryos response to different maturation media treatments.

Table 2. Effect of different media on germination of mature somatic embryos of F. esculentum.

\begin{tabular}{llc}
\hline Treatments & $\begin{array}{l}\text { Media } \\
\text { composition }\end{array}$ & $\begin{array}{c}\text { Somatic embryo germination } \\
\text { frequency (SEGF) } \\
\% \pm \text { S.E. }\end{array}$ \\
\hline SEGM1 & MS basal $+2 \%$ sucrose & $60 \pm 6.7$ \\
SEGM2 & $1 / 2$ MS basal $+2 \%$ sucrose & $28.89 \pm 5.9$ \\
SEGM3 & $1 / 2$ MS basal $+2 \%$ sucrose $+0.2 \mathrm{mg} / \mathrm{GA}_{3}$ & $13.31 \pm 3.9$ \\
SEGM4 & $1 / 2 \mathrm{MS}$ basal $+2 \%$ sucrose $+950 \mathrm{mg} / \mathrm{KNO}_{3}$ & 0 \\
\hline
\end{tabular}

Out of all the somatic embryos that were obtained, however, approximately $40-45 \%$ embryos showed abnormality with respect to their maturity, individuality and conversion to normal plantlets. Many of them developed as fused structures. Any attempt to separate them invariably led to the development of callus. Other abnormal embryos, which developed as individual entity but failed to mature and germinate properly, were subjected to shoot organogenesis. Initially meristemoid originated as morphogenic and bulbous structure at the top of the embryos within 3 weeks of inoculation onto MSIMs having various BAP concentrations (Fig. 4). As can be observed from results presented in Table 3, while MSIM with no BAP could not induce any 
meristemoid, MSIM with BAP $(0.1 \mathrm{mg} /$ to $0.5 \mathrm{mg} \Lambda)$ was able to induce meristemoids in $11.66-60 \%$ of abnormal embryos ( $0.2 \mathrm{mg} / \mathrm{BAP}$ induced highest i.e. in $60 \%$ of embryos).

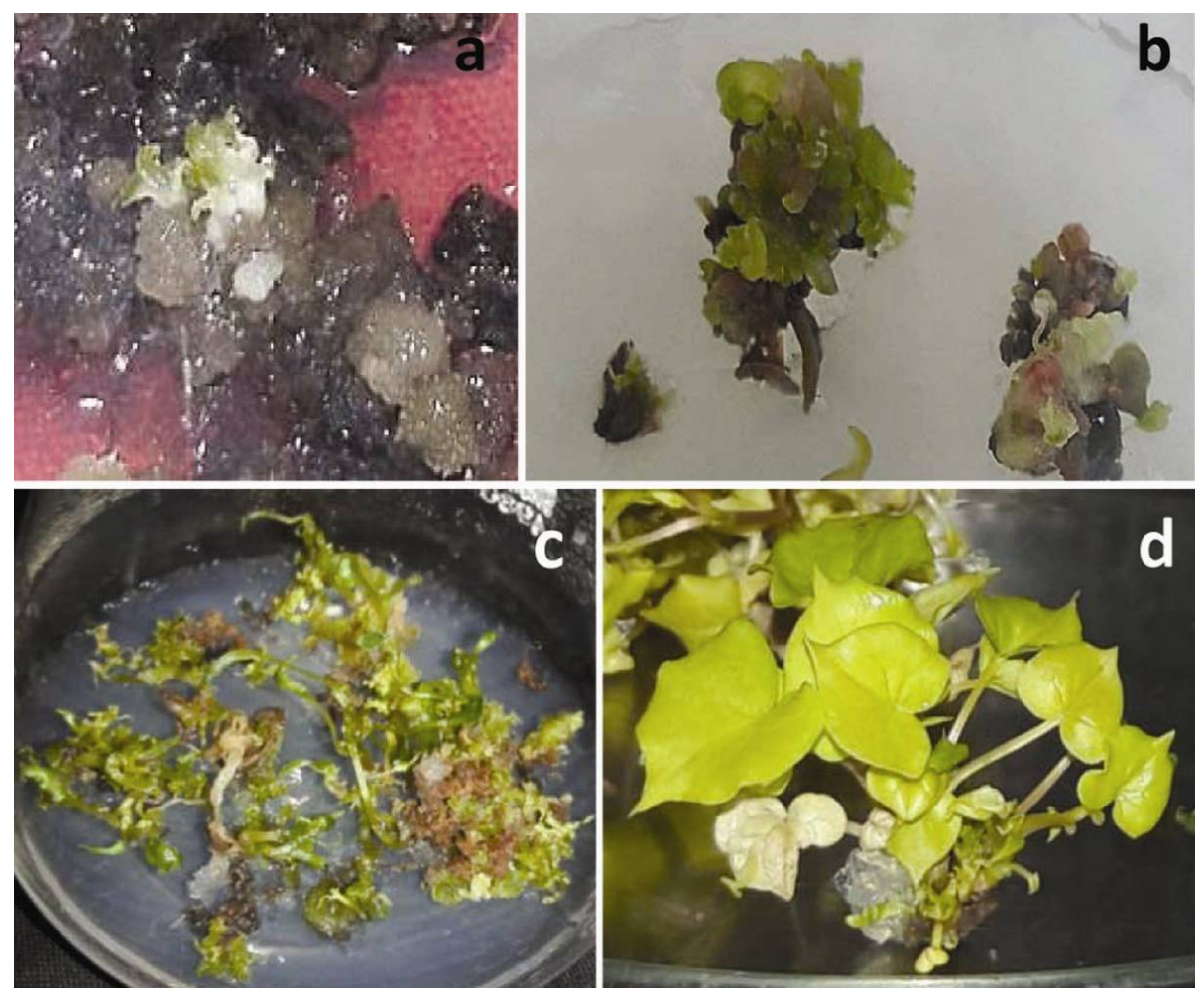

Fig. 4. Induction of meristemoids in abnormal embryos and progression of shoot buds in Fagopyrum esculentum. (a) Induction of conical meristemoids in fused embryos, (b) further proliferation of nodular and conical meristemoids, (c) various stages of shoot buds progression and development and (d) further branching and appearance of leaves in developing shoots.

When these meristemoid developed embryos were subcultured to their respective fresh media, they got enlarged, compact and slightly irregular in shape with occasional shoot bud differentiation. Thus all the induced meristemoids did not develop into shoot buds, but majority of them did. Around $30.33 \%$ of embryos with induced meristemoids over $0.2 \mathrm{mg} / \mathrm{BAP}$ progressed to shoot buds, which in turn developed in shoots. $29 \%$ of embryos with induced meristemoids developed in shoots in $0.3 \mathrm{mg} \Lambda \mathrm{BAP}$, while 0.4 and $0.5 \mathrm{mg} / \mathrm{BAP}$ induced shoots in $20 \%$ of abnormal embryos. In every case, however, the regenerated moderately elongated shoots and relatively shorter micro-shoots enclosed the entire surface of abnormal embryo apices within 2 weeks of culture and in the next two weeks, large numbers of micro-plants could be seen on them (Fig. 4). 
Table 3. Meristemoid induction and shoot induction response in abnormal embryos at different BAP concentrations.

\begin{tabular}{lll}
\hline $\begin{array}{c}\text { BAP concentration } \\
(\mathrm{mg} /)\end{array}$ & $\begin{array}{c}\text { Meristemoid induction } \\
\text { frequency } \% \pm \mathrm{SE}\end{array}$ & $\begin{array}{c}\text { Shoot induction frequency } \\
\% \pm \mathrm{SE}\end{array}$ \\
\hline 0 (control) & 0 & 0 \\
0.1 & $11.67 \pm 1.20$ & 0 \\
0.2 & $60.00 \pm 3.85$ & $30.33 \pm 3.85$ \\
0.3 & $43.22 \pm 4.98$ & $29 \pm 2.17$ \\
0.4 & $35.55 \pm 2.22$ & $20.11 \pm 2.41$ \\
0.5 & $25.77 \pm 3.11$ & $20 \pm 0$ \\
\hline
\end{tabular}

Most of such shoots were, however, not able to take up further growth and the base of some shoots started turning brown and senescing. That might be due to excessive ethylene production in the cultures. Silver nitrate has been reported to inhibit ethylene production and prevent senescence. Thus to overcome the problem of browning and to improve shoot growth, shoots were excised from those embryos and cultured on MS containing $\mathrm{AgNO}_{3}(0.1-0.5 \mathrm{mg} /$ ) either alone or with BAP (0.1 - $0.5 \mathrm{mg} /)$. There was a positive correlation between $\mathrm{AgNO}_{3}$ concentrations and frequency of shoots not getting brown and progressing to elongated, developed state at least in the concentration range of $0.2 \mathrm{mg} /$ ( $9.99 \%$ of shoots) to $0.5 \mathrm{mg} /$ ( $18.9 \%$ of shoots). $0.1 \mathrm{mg} / \mathrm{AgNO}_{3}$ did not show any progression of shoots development. BAP, however, was found to have a synergistic effect with $\mathrm{AgNO}_{3}$ on the in vitro development of shoots (Table 4). Out of all the concentrations tested, the greatest response $68.09 \%$ was observed at $0.5 \mathrm{mg} /$ level of $\mathrm{AgNO}_{3}$ and BAP.

Table 4. Effect of different concentrations of $\mathrm{AgNO}_{3}$ alone and in combination with BAP on shoot development frequency and senescence.

\begin{tabular}{cccc}
\hline $\begin{array}{c}\mathrm{AgNO} \\
\text { conc. }(\mathrm{mg} /)\end{array}$ & $\begin{array}{c}\text { BAP concentration } \\
(\mathrm{mg} \Lambda)\end{array}$ & $\begin{array}{c}\text { Shoot development } \\
\text { frequency }(\%) \pm \text { S.E. }\end{array}$ & $\begin{array}{c}\text { Status of } \\
\text { senescence }\end{array}$ \\
\hline 0 & - & 0 & ++ \\
0.1 & - & 0 & ++ \\
0.2 & - & $9.99 \pm 3.33$ & + \\
0.3 & - & $14.44 \pm 1.11$ & + \\
0.4 & - & $13.89 \pm 3.38$ & + \\
0.5 & - & $18.88 \pm 4.01$ & No senescence \\
0.1 & 0.1 & $27.14 \pm 3.45$ & $\prime$ \\
0.2 & 0.2 & $35.55 \pm 2.22$ & $\prime \prime$ \\
0.3 & 0.3 & $40.55 \pm 0.55$ & $\prime \prime$ \\
0.4 & 0.4 & $54.44 \pm 2.94$ & $\prime \prime$ \\
0.5 & 0.5 & $68.09 \pm 2.71$ & $\prime$
\end{tabular}

‡Degree of senescence: + + highest to + lowest. 
In vitro raised shoots were transferred to root induction media (RIMs). The effect of IBA on rooting varied with ionic strength of MS. MS (RIM1 and RIM3) did not show any root induction with or without IBA. The shoot bases swelled up but no roots were observed. Half strength MS (RIM2 and RIM4), however, without and with IBA induced roots in 66.7 and $88.9 \%$, respectively of excised shoots cultured over them (Table 5).

Table 5. Effect of different strengths of MS and IBA on root induction frequency in cultured shoots of F. esculentum.

\begin{tabular}{lll}
\hline Treatments & Media composition & $\begin{array}{c}\text { Root induction frequency } \\
\% \pm \mathrm{SE}\end{array}$ \\
\hline RIM1 & MS $+2 \%$ sucrose & 0 \\
RIM2 & Half strength $\mathrm{MS}+2 \%$ sucrose & $66.66 \pm 3.85$ \\
RIM3 & MS $+2 \%$ sucrose $+0.25 \mathrm{mg} /$ IBA & 0 \\
RIM4 & Half strength $\mathrm{MS}+2 \%$ sucrose +0.25 & $88.89 \pm 5.88$ \\
& $\mathrm{mg} /$ IBA & \\
\hline
\end{tabular}

It was easier to remove traces of gelling agent after the transfer of plantlets to Hoagland solution. Further, their elongation and growth in Hoagland solution (Fig. 5a) indicated that plantlets have started photosynthesizing and are changing from photoheterotrophic to photoautotrophic mode. After the transfer of plantlets to cups containing potting mix, plantlets continued to grow, as reflected by emergence of new leaves. Pores created in the covering polythene bags helped them strengthen their water
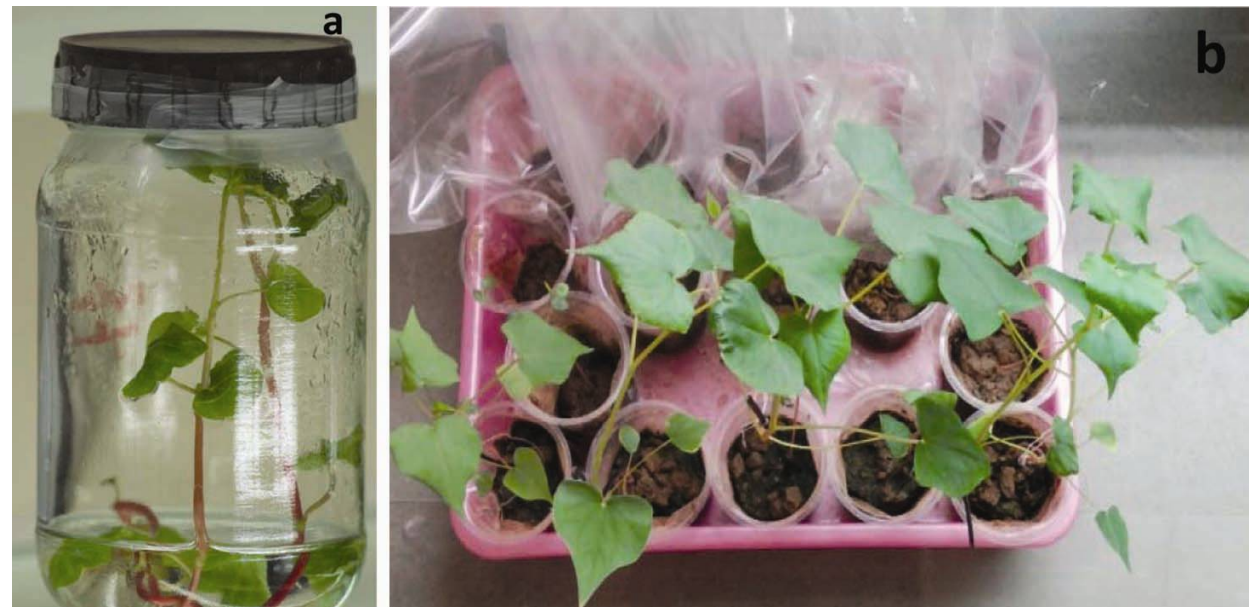

Fig. 5. Acclimatization of in vitro regenerated F. esculentum plantlets. (a) Growth of plantlet from rooting medium after transfer to Hoagland solution in jam bottle and (b) plants after transfer to potting mix; different stages of polythene bag removal and healthy growth of plants can be seen. 
balance. Bags were gradually removed when the plants became effectively acclimatized to soil pots. Fig. 5b shows acclimatization of in vitro regenerated plantlets in buckwheat. Successfully acclimatized plants were transferred to field where they grew well and exhibit phenotypic homogeneity when compared to seed-derived plants. All the plants flowered well and set seeds.

\section{Acknowledgements}

Authors thankfully acknowledge the infrastructure and other laboratory support provided by Jaipur National University, Jaipur. First author (RS) is particularly grateful to School of Life Sciences, Jaipur National University to allow her to pursue her academic research program and to conduct all the experiments pertaining to this work.

\section{References}

Adachi T, Yamaguchi A, Miike Y and Hoffmann E (1989) Plant regeneration from protoplasts of common buckwheat (Fagopyrum esculentum). Plant Cell Rep. 8: 247-250.

Berbec A and Doroszewska T (1999) Regeneration in vitro of three cultivars of buckwheat (Fagopyrum esculentum Moench.) as affected by medium composition. Fagopyrum 16: 49-52.

Chen C, Lan J, Xie S, Cui S and Li A (2012) In vitro propagation and quality evaluation of longterm micro-propagated and conventionally grown Fagopyrum dibotrys Hara mutant, an important medicinal plant. J. Med. Plants Res. 6: 3003-3012.

Couch J, Naghski J and Krewson C (1946) Buckwheat as a source of rutin. Science 103: 197-198.

Dorrell OG (1970) Fatty acid composition of buckwheat seed. J. Am. Oil Chem. Soc. 48: 693- 696.

Gamborg OL, Miller RA and Ojima (1968) Nutrient requirements of suspension cultures of soybean root cells. Exp Cell Res. 50: 151-158.

Ganeshpurkar A and Saluja AK (2017) The pharmacological potential of rutin. Saudi Pharm J. 25: $149-164$.

Griffith JQ, Couch JF and Lindauer MA (1944) Effect of rutin on increased capillary fragility in man. Proc. Soc. Exp. Biol. Med. 55: 228-229.

Gumerova EA, Galeeva EI, Chuyenkova SA and Rumyantseva NI (2003) Somatic embryogenesis and bud formation on cultured Fagopyrum esculentum hypocotyls. Russ. J. Plant Physiol. 50: 640-645.

Han MH, Kamal AHM, Huh YS, Jeon AY, Bae JS, Chung KY, Lee MS, Park SU, Jeong HS and Woo SH (2011) Regeneration of plantlet via somatic embryogenesis from hypocotyls of Tartary Buckwheat (Fagopyrum tataricum). Aust. J. Crop Sci. 5: 865-869.

Hou S, Z Sun, B Linghu, Y Wang, K Huang, D Xu and Y Han (2014) Regeneration of buckwheat plantlets from hypocotyl and the influence of exogenous hormones on rutin content and rutin biosynthetic gene expression in vitro. Plant Cell Tissue Organ Cult. 120: 1159-1167. 
Jiang P, Burczynski F, Campbell C, Pierce G, Austria JA and Briggs CJ (2007) Rutin and flavonoid contents in three buckwheat species Fagopyrum esculentum, F. tataricum, and F. homotropicum and their protective effects against lipid peroxidation. Food Res. Int. 40: 356-364.

Jin H, Jia J and Hao J (2002) Efficient plant regeneration in vitro in buckwheat. Plant Cell Tissue Organ Cult. 69: 293-295.

Kachonpadungkitti Y, Romchatngoen S, Hasegawa K and Hisajima S (2001) Efficient flower induction from cultured buckwheat (Fagopyrum esculentum L.) node segments in vitro. Plant Growth Regul. 35: 37-45.

Kawa JM, Taylor CG and Przybylski R (2003) Buckwheat concentrate reduces serum glucose in streptozotocin-diabetic rats. J Agri Food Chem. 51: 7287-7291.

Klcova L and Gubisova M (2008) Evaluation of different approaches to Buckwheat (Fagopyrum esculentum Moench.) micropropagation. Czech J. Genet. Plant Breed. 44: 66-72.

Kumar M and Saraswat R (2018) Plant regeneration and genetic transformation in buckwheat (Fagopyrum spp.), A multipurpose gluten free crop of high nutraceutical importance: A critical review. Annals of Plant Sciences. 7: 1954-1963.

Kwon SJ, Han MH, Huh YS, Roy SK, Lee CW and Woo SH (2013) Plantlet regeneration via somatic embryogenesis from hypocotyls of common buckwheat (Fagopyrum esculentum Moench.). Korean J. Crop Sci. 58: 331-335.

Lachmann S and Adachi T (1990) Callus regeneration from hypocotyl protoplasts of tartary buckwheat (Fagopyrum tatericum Gaertn.) Fagopyrum 10: 62-64.

Lee SY, Kim YK, Uddin MD R, Park NI and Park SU (2009) An efficient protocol for shoot organogenesis and plant regeneration of buckwheat (Fagopyrum esculentum). Romanian Biotechnological Letters. 14: 4524-4529.

Li SQ and Zhang QH (2001) Advances in the development of functional foods from buckwheat. Crit. Rev. Food Sci. Nutr. 41: 451-464.

Luthar Z and Marchetti S (1994) Plant regeneration from mature cotyledons in buckwheat (Fagopyrum esculentum Moench) germplasm collection. Fagopyrum 14: 65-69.

Majid A, Kaloo ZA, Padder BM and Munshi AH (2015) An efficient in vitro regeneration protocol for an endandered medicinally important herb Fagopyrum dibotrys growing in Kashmir Himalaya. CIB Tech. J. Biotechnology 4: 2319-3859.

Michalova A, Dotlaci il L and Cejka L (1998) Evaluation of common buckwheat cultivars. Advances in Buckwheat Research. Proceedings of the VII International Symposium on Buckwheat. I97-I108.

Morris MR (1951) Cytogenetic studies on buckwheat. Genetic and cytological studies of compatibility in relation to heterostyly in common buckwheat, Fagopyrum sagittatum. J. Hered. 42: 85-89.

Neskovic M, Vujicic R and Budimir S (1987) Somatic embryogenesis and bud formation from immature embryos of buckwheat (Fagopyrum esculentum Moench.). Plant Cell Rep. 6: 423-426. 
Neskovic M, Vujicic R and Budimir S (1995) Somatic embryogenesis in buckwheat (Fagopyrum Mill.) and sorrel (Rumex L.), Polygonaceae. Somatic Embryogenesis and Synthetic Seed II, Springer-Verlag, Berlin. 13: 412-427.

Oba S, Suzuki Y and Fujimoto F (1998) Breaking strength of pedicel and grain shattering habit in two species of buckwheat (Fagopyrum spp.). Plant Prod. Sci. 1: 62-66.

Park CH, Lee SL, Chung CS, Shin YB, Kim NS, Kim YB, Yoon KM and Choi YS (1999) Somatic embryogenesis and plant regeneration from leaf and stem explants of buckwheat. Fagopyrum. 16: 53-56.

Slawinska J, Kantartzi SK and Obendrof RL (2009) In vitro organogenesis of Fagopyrum esculentum Moench (Ploygonaceae) as a method to study seed set in buckwheat. European Journal of Plant Science and Biotechnology 3: 75-78.

Srejovic V and Neskovic M (1981) Regeneration of plants from cotyledon fragments of buckwheat (Fagopyrum esculentum Moench.). Z Pflanzenphysiol. 104: 37-42.

Trolinder NL and Goodin JR (1987) Somatic embryogenesis and plant regeneration in cotton (Gossypium hirsutum L.). Plant Cell Rep. 6: 231- 234.

Wang CL, Dong XN, Ding MQ, Tang YX, Zhu XM, Wu YM, Zhou ML and Shao JR (2016) Plantlet regeneration of tartary buckwheat (Fagopyrum tataricum Gaertn.) in vitro tissue cultures. Protein and Pept Lett. 23: 468-477.

Woo SH, Nair A, Adachi T and Campbell CG (2000) Plant regeneration from cotyledon tissues of common buckwheat (Fagopyrum esculentum Moench). In Vitro Cell Deve Biol Plant. 36: 358-361.

Woo SH, Takaoka M, Kim HS, Park CH, Adachi T and Jong SK (2004)Plant regeneration via shoot organogenesis from leaf callus culture of common buckwheat (Fagopyrum esculentum Moench.). Proceedings of the 9th Inernational Symposium on Buckwheat, Prague. 61-65.

Woo SH, Roy SK, Kwon SJ, Cho SW, Sarker K, Lee MS, Chung KY and Kim HH (2016) Concepts, Prospects, and Potentiality in Buckwheat (Fagopyrum esculentum Moench): A Research Perspective. Molecular Breeding and Nutritional Aspects of Buckwheat. London. 321-325.

Yamane Y (1974) Induced differentiation of buckwheat plants from subcultured calluses in vitro. Jpn. J. Genet. 49: 139-146.

(Manuscript received on 2 March, 2019; revised on 7 April, 2019) 